\title{
Corticotomy assisted enmasse retraction
}

Abdul Rehman Ahmed Khan ${ }^{1}$, Praveen Kumar Neela², Vasu Murthy Sesham ${ }^{3}$, Shiva Prasad Mandaloju ${ }^{4}$, Sreekanth Keesara ${ }^{5}$

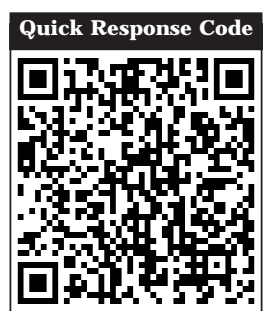

doi: $10.5866 / 2015.7 .10302$

1Post Graduate Student

${ }^{2}$ Reader

${ }^{3}$ Prof \& HOD

${ }^{4}$ Senior Lecturer

${ }^{5}$ Senior Lecturer

Department of Orthodontics and Dentofacial

Orthopaedics,

Kamineni Institute of Dental Sciences,

Narketpally, Nalgonda, Telangana.

\section{Article Info:}

Received: October 7, 2015

Review Completed: November 9, 2015

Accepted: December 10, 2015

Available Online: March, 2016 (www.nacd.in)

(C) NAD, 2015 - All rights reserved

\section{Email for correspondence:}

dr_rehmankhan007@yahoo.com

\begin{abstract}
:
As the field of orthodontics is progressing day by day, the patients are interested in getting their orthodontic treatment finished as early as possible. Hence, many attempts are being made to fasten the orthodontic tooth movement. Corticotomy or (PAOO) is one of the procedure which fastens the treatment time and gives faster results when compared to the traditional orthodontic therapy. PAOO is a combination of a selective alveolar decortication, particulate bone grafting followed by application of orthodontic forces. This article shows a case treated with Corticotomy to fasten the retraction so as to reduce the overall orthodontic treatment.
\end{abstract}

Key words: Periodontally Accel erated Osteogenic Orthodontics, Corticotomy Assisted Orthodontics, Piezotome.

\section{Introduction:}

Traditional orthodontic therapy typically takes longer duration of time to achieve desired results and in present day scenario where patients are eager to get their orthodontic treatment completed as early as possible, corticotomy procedure also known as Periodontally Accelerated Osteogenic Orthodontics (PAOO) fastens the treatment time when compared to traditional orthodontic therapy. This method claims to have several advantages whichincludes a reduced treatment time, enhanced expansion, differential tooth movement, increased traction of impacted teeth and, finally, more post-orthodontic stability. With this technique, one is no longer at the mercy of the pre existing alveolar volume, and teeth can be moved 2 to 3 times further in $1 / 3$ rd to 1/4th the time required for traditional orthodontic therapy. ${ }^{1}$ Generally, we can divide the orthodontic treatment in three stages: 
- Stage I: Alignment and leveling.

- Stage II: Space closure.

- Stage III: Finishing and settling.

Since it has been observed that the Stagell i.e., the retraction stage or the stage in which the extraction spaces are closed comparatively takes longer duration of time i.e., approximately half of the total orthodontic treatment time.

\section{Case report:}

A 20 year old female patient reported to the Department of Orthodontics and Dentofacial Orthopaedics with the chief complaint of forwardly placed upper front teeth. On extra oral clinical examination patient had a mesocephalic shape of the head with mesoprosopic facial form, profile of the patient was convex with acute nasolabial angle. Intra oral examination revealed Angle's class I molar relation and a class I canine relation on both the sides with severely proclined upper and lower anteriors. Hence, based on the clinical findings the case has been diagnosed as Angle's class I malocclusion with bimaxillary dentoalveolar proclination.

Treatment plan included extraction of 14,24 , 34, 44 followed by banding of Banding of I and II molars and bonding of remaining teeth using pre adjusted edgewise appliance 0.022 slot MBT prescription. Initial alignment and leveling was started with $0.014 \mathrm{NiTi}$ arch wire and continued till $0.019 \times 0.025$ inch SS wire. All the necessary records were made which included photographs, study models, Orthopantomogram and lateral cephalogram (F igure $1 \mathrm{~A}-\mathrm{G}$ ) once the alignment and leveling was completed. As the patient was insisting to get her overall treatment completed as early as possible Corticotomy procedure was explained to the patient as a treatment option. Once the patient agreed for the procedure, consent was taken from her. The patient was then referred to Department of Periodontics for performing Corticotomy in both maxillary and mandibular arch.

Surgical procedure: To perform corticotomy in both upper arch and lower arch, full-thickness mucoperiosteal flaps were reflected to provideaccess to underlying alveolar bone by using sulcular incisions and vertical releasing incisions. Peizotomewas used to make decortications in the alveolar bone. A vertical groove was placed in the interradicular space, midway between the root prominences in the alveolar bone. This groove was extended from a point 2 to $3 \mathrm{~mm}$ below the crest of the bone to a point $2 \mathrm{~mm}$ beyond the apices of the roots about $1.5-2 \mathrm{~mm}$ in depth. These vertical corticotomies were then connected with a semicircular-shaped corticotomy in the apical region.Grafting with bioactive glass was done in the areas that have undergone corticotomies(Figure $2 \mathrm{~A}$ $\& 2 \mathrm{~B}$ ).The volume of the graft material used was dictated by the direction and amount of tooth movement predicting the pre-treatment thickness of the alveolar bone, and the need for labial support by the alveolar bone. Finally suturing was done in both maxillary and mandibular arch.

Suture removal was done 10 days after the corticotomy procedure and the patient was recalled to the Department of Orthodontics and Dentofacial orthopedics for force application in both maxillary and mandibular arch. A force of $200 \mathrm{gm}$ was applied on both right side and left side in both maxillary and mandibular arch, the patient was recalled once in every four weeks and the amount of extraction space remaining was noted down, the force application was continued by changing the active tie backs once in a month till the entire spaces got closed in both the arches. The observations of the present case report indicates that the average rate of en masse retraction was $1.5 \mathrm{~mm}$ per month which is comparatively more when compared to non corticotomy assisted en masse retraction where in it will be only 0.5 to $0.8 \mathrm{~mm}$ per month. It was observed that the faster rate of retraction was observed mainly during first three months which then gradually slows down. However the entire extraction space of $7 \mathrm{~mm}$ per side in both maxillary and mandibular arch got closed within a period of 5months.

After the entire spaces got closed in both maxillary and mandibular arches again necessary 


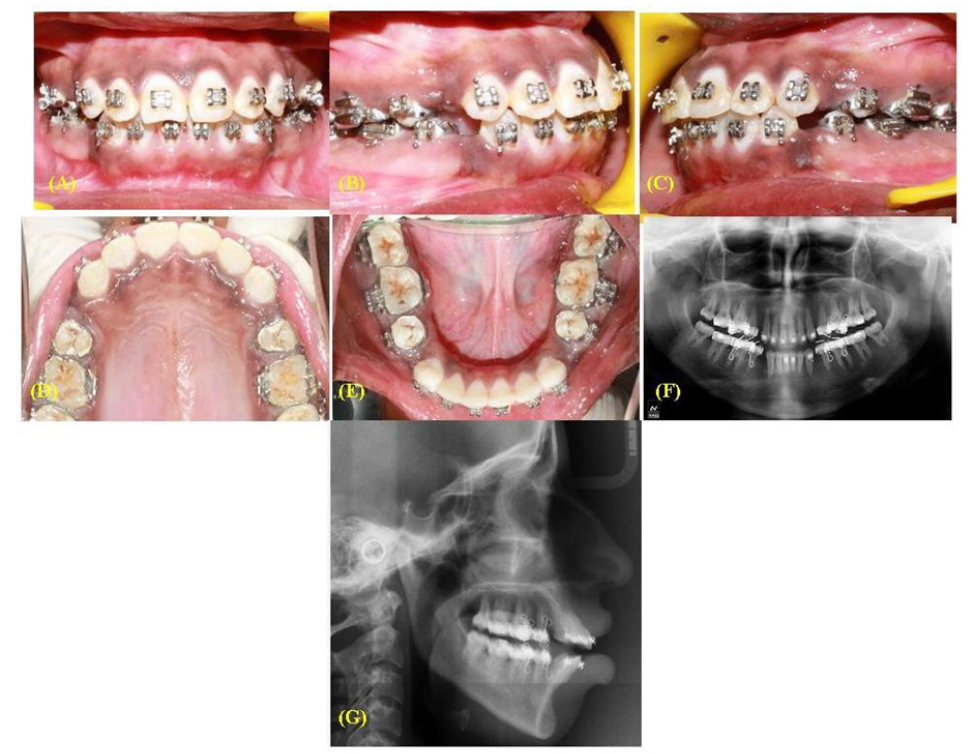

Figurel: A-G: Pre Corticotomy records. A) Frontal, B) Right lateral, C) Left lateral, D) Maxillary occlusal, E) Mandibular occlusal, F) Orthopantomogram, G) Lateral cephalogram
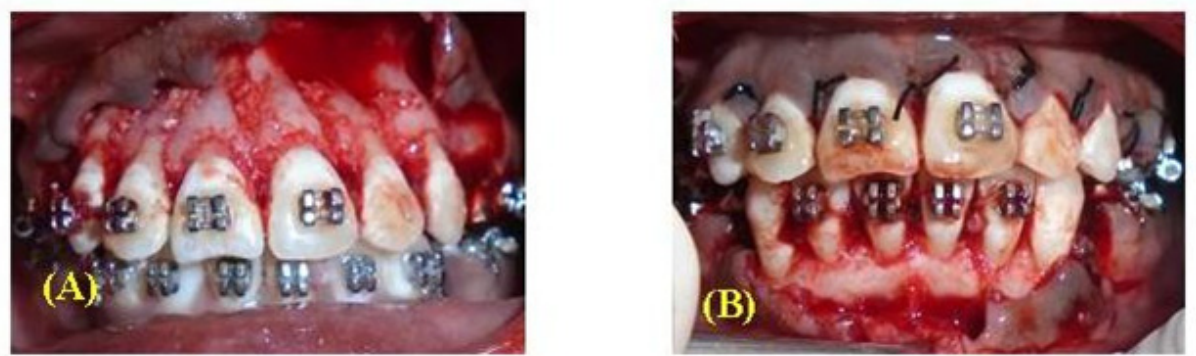

Figure 2: A-B: Corticotomy procedure. A) Corticotomy cuts in maxillary arch, B) Corticotomy cuts in mandibular arch.

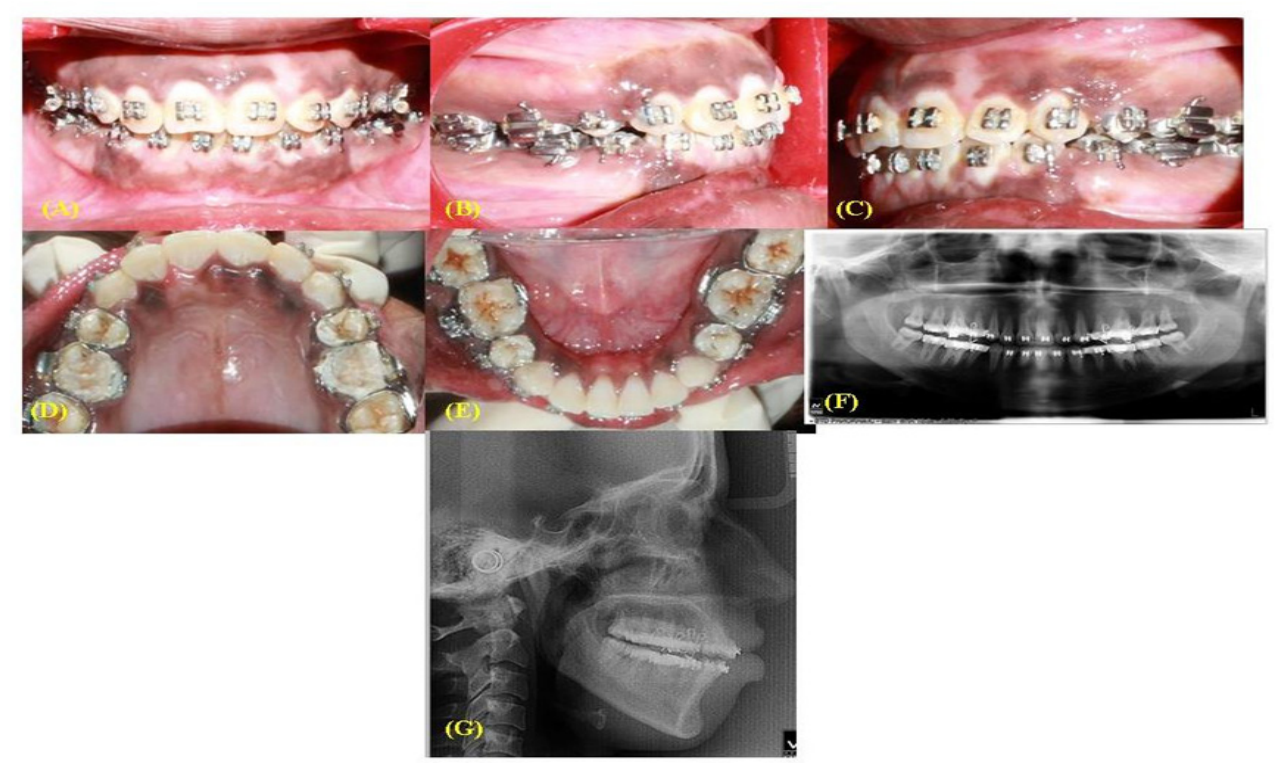

Figure 3: A-G: After space closure records. A) Frontal, B) Right lateral, C) Left lateral, D) Maxillary occlusal, E) Mandibular occlusal, F) Orthopantomogram, G) Lateral cephalogram. 
records were made which included photographs, study models, Orthopantomogram and Iateral cephalogram (Figure $3 \mathrm{~A}-\mathrm{G}$ ).

\section{Discussion:}

There is an increase in tooth mobility during corticotomy assisted orthodontic treatment due to the transient osteopenia without a change in bone matrix vol ume. It is generally accepted that heavier forces must be applied in cases of "bone block" movement after corticotomy to move the tooth-bone block. However, it has been reported that conventional orthodontic forces are sufficient in Corticotomy Assisted Orthodontics because forces are not concentrated in either the tooth-periodontal complex surrounded by a rigid bone structure or in the bone-tooth block delimitated by corticotomy, but is distributed on the tooth-periodontal-trabecular bone (low-density transitory trabecular bone.This better distributed mechanical loading may be the reason why corticotomy-assisted tooth movement is associated with a reduced period of PDL hyalinization on the compression side compared to conventional movement. ${ }^{2}$ Since, it has been observed that the Stagell i.e., the retraction stage or the stage in which the extraction spaces are closed comparatively takes longer duration of time i.e., about 40 to 50 percent of the total orthodontic treatment time corticotomy was performed when the patient was in the retraction stage of the treatment. The faster rate of space closure with Corticotomy could beattributableto the fact that as moreamount of optimal tooth movement requires the combination of well planned orthodontic forces and an alveolar bone that offers less resistance to movement, i.e., less dense bone and increased bone metabolism so when alveolar bone metabolism is increased, by performing corticotomy the orthodontic tooth movement is accel erated. Change in bone physiol ogy would result in a localized decrease in trabecular bone density, which in turn, would offer less resistance to tooth movement. ${ }^{3-5}$

\section{Conclusion:}

Corticotomy assisted enmasse retraction has proved to be faster than non corticotomy assisted enmasse retraction.

\section{References:}

1. Goyal Amit, Kalra J PS, Bhatiya Pankaj, Singla Suchinder and Bansal Parul. Periodontally accelerated osteogenic orthodontics (PAOO) - a review. J Clin Exp Dent 2012; 4(5):292-296.

2. J. Cano, J. Campo, E. Bonilla, C. Colmenero.Corticotomyassisted orthodontics. J Clin Exp Dent 2012; 4(1):54-59.

3. H. Nowzari, F.K. Yorita and H.C. Chang. Periodontally accelerated osteogenic orthodontics combined with autogenous bone grafting. Compend Contin Educ Dent 2008; 29:200-206.

4. Twaddle BA, Ferguson DJ, Wilcko WM.Dento-alveolar bone density changes following corticotomy-facilitated orthodontics. J Dent Res 2002; 80:301.

5. Wilcko MW, Ferguson DJ, Bouquot J E, Wilcko MT. Rapid orthodontic decrowding with alveolar augmentation: Case report. World J Orthod. 2003; 4(3):197-205.

\section{Gain quick access to our journal online View our journal at www.nacd.in}

